\title{
LV-OP-4-6
}

\section{Institutional experience and clinical outcomes of robotic major hepatectomy for liver tumors}

Iswanto SUCANDY*, Sharona ROSS, Valerie PRZETOCKI, Cameron SYBLIS, Kaitlyn CRESPO, Timothy BOURDEAU, Alexander ROSEMURGY

Digestive Health Institute, AdventHealth Tampa, Tampa, FL, USA

Introduction: The majority of published literature has only reported outcomes of robotic minor non-anatomical hepatectomy. We aim to examine our clinical outcomes, safety, and feasibly with robotic major hepatectomy.

Methods: We prospectively followed 235 patients who underwent robotic hepatectomy since 2016. Major hepatectomy is defined as a resection of $\geq 3$ segments. Data are presented as median (mean $\pm \mathrm{SD}$ ).

Results: Of the 235 patients, 142 of the patients underwent a major hepatectomy. Median age was 63 (61 \pm 14.0$)$ years, 51\% were women, BMI was $28(29 \pm 6.1) \mathrm{kg} / \mathrm{m}^{2}$ and ASA Class was $3(3 \pm 0.5) .25 \%$ of operations were for metastatic colorectal cancer, $23 \%$ for hepatocellular carcinoma, 11\% cholangiocarcinoma, and 6\% for gallbladder adenocarcinoma. Regarding the type of resection, 15 patients (11\%) had central hepatectomy, 30 (21\%) had formal right, 41 (29\%) had formal left, 31 (22\%) had non-anatomical right, 11 (8\%) had non-anatomical left, 7 (5\%) had extended right, and 7 (5\%) had extended left. Prep time (in the room until incision) 64 (74 \pm 67.3 ) minutes, Extraction time (incision until specimen extraction) 138 (159 \pm 99.3) minutes, Console time 198 (213 \pm 119.8$)$ minutes, Closure time (extraction until dressing placement) $106(214 \pm 271.3)$ minutes, Operative duration was $288(305 \pm 119.0)$ minutes and time under anesthesia $359(369 \pm 115.6)$ minutes. Estimated blood loss was $200(258 \pm 252.1) \mathrm{mL}$ and length of stay was $4(5 \pm 2.7)$ days. 9 patients experienced postoperative complications (4 ileus, 1 pneumonia, 1 bile leak, 1 gram-negative bacteremia, 1 jaundice, 1 pneumothorax). 22 patients were readmitted within 30 days with one death after readmission, due to aspiration.

Conclusions: Application of the robotic platform to major hepatectomy is safe and feasible with excellent perioperative outcomes. 